\title{
A Gravity Model Analysis of FDI across EU Member States
}

\author{
Alena Dorakh ${ }^{1+}$ \\ ${ }^{1}$ Trier University, Germany
}

\begin{abstract}
While recent debates about European integration focus mainly on the losses from dissolutions, a remarkable rise in foreign direct investment (FDI) in the accession countries has become increasingly evident as a benefit of the European Union (EU) membership, which makes EU membership a key FDI determinant. By applying an augmented gravity model (rather than standard gravity variables), covering 39 host and home countries over 1991-2017, we investigated specific factors in explaining FDI inflows, with a focus on the new member EU states. Empirically, we created a series of ordinary least squares and Poisson Pseudo-Maximum-Likelihood models to account for all country-time-specific and country-pair factors. This paper verifies that EU membership has a positive and significant effect on FDI, between 1991 and 2017 FDI inflows became greater, on average, by approximately $23 \%$. After EU enlargement, more FDI came from EU members to the new EU member countries and less came from non-EU member countries.
\end{abstract}

Keywords: FDI, new member EU states (NMS), zero flows, fixed effects, Chinese investment

JEL Classifications: F15, F21, O52

Received 21 December 2019, Revised 27 April 2020, Accepted 29 June 2020

\section{Introduction}

For years, the European Union (EU) has been the largest destination for foreign direct investment (FDI). At the same time, it has been the leading outflow investor in the world, accounting for more than one third (35\%) of the world's inflows and about two fifths (41\%) of global outflows. According to OECD data, since 2018 FDI to the EU declined in line with the downward trajectory of global investment. However, the EU's share of global FDI inflows is always stable and accounted for $22 \%-23 \%$ in $2017-2018$.

While FDI flows to the EU as a whole decreased, investment in the new EU member states (NMS) increased by an average of 10\% in 2016-2018 (Figure 1). In fact, since Poland, Hungary, the Czech Republic, and other Central and Eastern European Countries (CEECs) joined the EU in 2004, FDI inflows rose sharply, reaching almost $\$ 49$ billion in 2018. Seemingly, NMS stand to benefit from joining the EU, making EU membership one of the most influential FDI determinants. 
Figure 1. Foreign direct investment inflows to the european union (EU) and new EU member states (USD million)

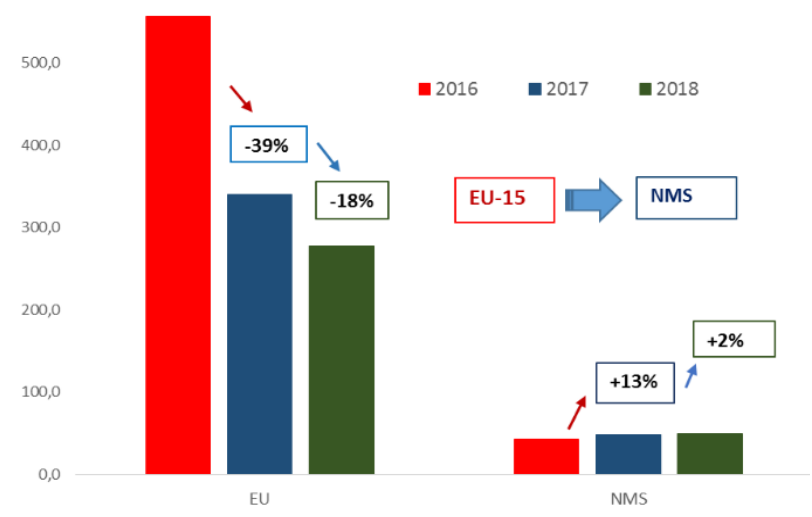

(Source) Calculated and drawn by the author based on World Bank and OECD data.

More than $70 \%$ of FDI to the NMS come from a few large investors within the EU. The leading investment partners are Germany, France, Austria, the Netherlands, and Luxembourg. The most attractive destinations are Poland, Hungary, the Czech Republic, and Slovakia.

Before the EU enlargement in 2004, EU founders and early members enjoyed the lowest trade and operation costs compared with the largest non-EU economies (the U.S., China, Japan, and Russia), as well as compared with the rest of the world. Within the enlarged EU, the accession countries offered new markets, competitive production costs, and relatively low limitations for the flow of goods and capital across borders. Basically, with the formation of the EU, trade and FDI fell between EU and non-EU members, while intra-EU FDI rose. FDI inflows to NMS have increased drastically. Thus, EU membership had a prominent role in fostering FDI growth in the NMS. Furthermore, FDI inflows have grown much faster than either GDP or trade in the EU (Figure 2).

Figure 2. Growth of the EU's GDP, FDI inflow, and trade

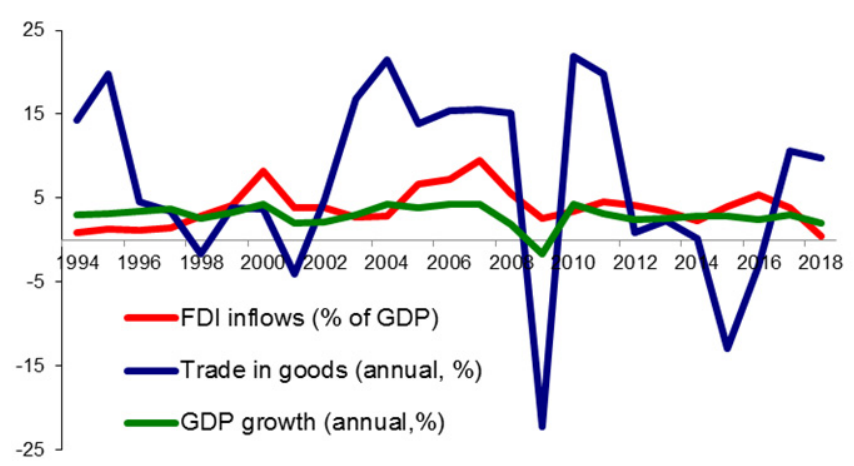

(Source) Calculated and drawn by the author based on the World Bank and OECD data. 
Figure 2 identifies the important links connecting FDI and GDP growth: the richer and larger countries became, the bigger and more intense the FDI inflows that occur. Economy size matters. It is clear evidence of strong gravity in the FDI patterns. Meanwhile, differences in trade and FDI growth assume that FDI is mainly complementary to trade, rather than a substitute for it. Low trade costs and cost of production, which capture differences in factor endowments, facilitate more FDI. Similarly, higher labor cost makes the cost of production larger and reduces FDI. For accession countries in the EU enlargement, the most relevant FDI determinants are market-seeking (horizontal FDI) and efficiency-seeking (vertical FDI).

EU enlargement was not a single event, and it continued for some time, designing new determinants and forms of FDI across countries over time. Besides traditional forms of FDI, further relaxation of FDI frictions in current integrations also triggered investment in technology capital.

This coincided with the remarkable rise of Chinese investment in the framework of EU-China technology transfer. While developed countries still account for the dominant part of the EU's FDI inflows, the share of Chinese investment in the EU has doubled over the last five years. This produced a new knowledge-capital model of FDI, as well as a complex vertical FDI strategy. In recent years, policymakers in the EU have liberalized their policies to attract more FDI. At the same time, they screen purchases by foreign companies that target Europe's assets. In other words, governments are increasingly interested in the determinants and reasons for FDI activity in the EU, and particularly in the NMS.

The goal of this paper is to examine the patterns of FDI across the EU; to identify FDI determinants in selected EU member countries; and, most importantly, to estimate whether and how much EU membership promotes FDI to accession countries.

Stimulated by the influential FDI and trade papers that evaluate FDI determinants, we created a gravity model for 6 host and 33 source countries over the period 1991-2017. The key adjustment that we proposed to gravity estimates is to allow for possible simultaneous FDI diversion as well as FDI creation of EU membership in the EU countries. Our empirical analysis provides solutions for challenges in gravity estimation, such as not accounting for multilateral resistance, the omission of zero and negative observations, and endogeneity of EU variables, which lead to severe estimation bias. Capitalizing on the latest literature, we propose a comprehensive estimating gravity specification with a full set of fixed effects that simultaneously identify the impact of bilateral and unilateral FDI determinants. The paper is structured as follows. In Section II, we provide the most influential FDI theories and review the empirical literature on FDI determinants. In Section III, we describe the stages of the analysis and report our empirical results. Section IV includes conclusions and policy implications. 


\section{Theoretical Background of the FDI}

\section{A. Theories of FDI}

FDI is a complex phenomenon that cannot be explained by a single universal theoretical model. Determinants of FDI vary across countries and regions and change their nature over time. They are better understood using a variety of theories, which are mostly derived from the Neoclassical Trade Theory with the New Trade Theory (NTT), as well as from Theory of industrial organization (Figure 3).

Figure 3. Theories and conceptual frameworks of FDI

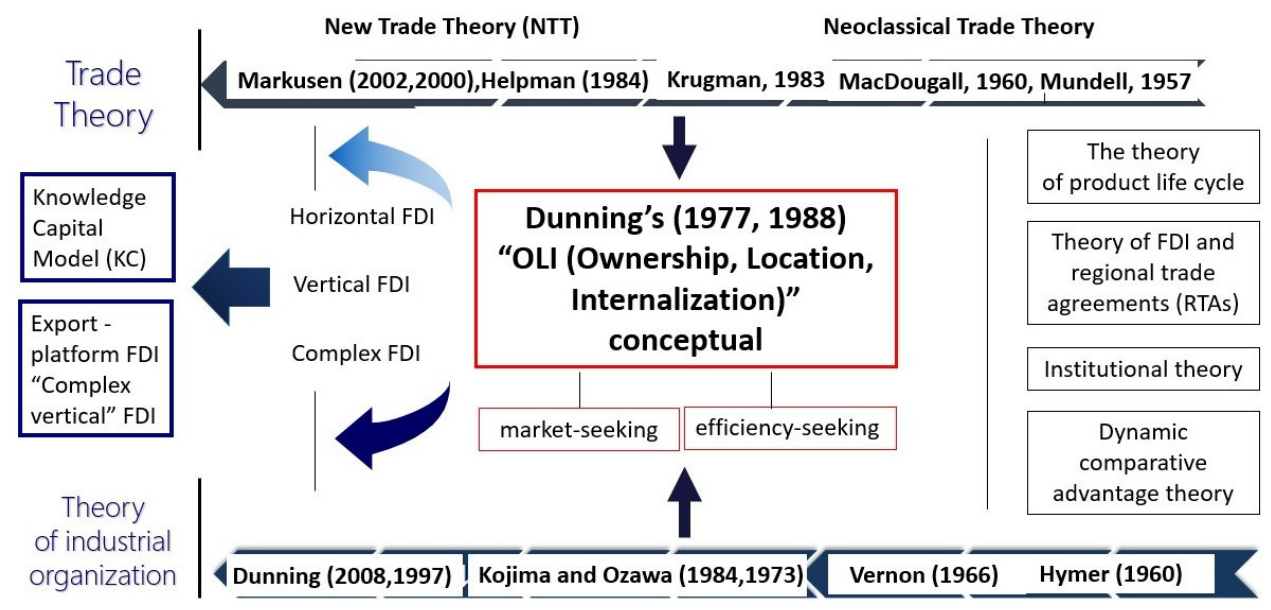

(Source) Drawn by the author.

As seen in Figure 3, until the 1950s, FDI was entirely explained within the traditional neoclassical theory of international capital movements (MacDougall, 1960; Mundell, 1957), where FDI is a result of capital flowing from the capital-abundant countries to the capital-scarce countries. In fact, FDI between countries of similar size and relative factor endowments are not observable. However, over the last five decades, developed countries, which are capitalabundant, have received a larger share of FDI flows (World Investment Report, 2018). Another critical point of neoclassical FDI theory is that under perfect competition a firm is not considered as an independent economic agent that confronts the theory of industrial organization.

Alternatively, within the theory of industrial organization, many conceptual frameworks have been proposed to explain why firms internationalize production and become multinational corporations (MNCs) (Figure 3). One of them is the theory of product life cycle, which was developed by Vernon (1966). According to this theory, firms begin FDI activity abroad when an innovative product reaches maturity in the source country. Initially, firms create a product 
for the domestic market and export the surplus. Then, to become more competitive domestically, the producer invests in manufacturing facilities in other countries. While this theory explains the shift from export to FDI, it does not sufficiently explain the determinants of FDI. In this case, FDI is motivated by firm-specific factors without a consideration for the local factors of host countries.

The shortcomings of the previous theories led to Dunning's (1977) "OLI (Ownership, Location, Internalization)" conceptual framework that later became a canon of FDI determinants, integrating elements from trade and international business literature. According to the theory, there are two main reasons for firms to become MNCs: market-seeking and efficiency-seeking. The first type of FDI activity implies that firms intend to overcome the geographical and cultural distance between countries for getting access to new foreign markets. The second type of FDI implies the investment activity between countries based on a difference in relative factor endowments.

From the late 1970s, following the development of the NTT, MNCs become visible, and FDI determinants were explicitly modeled. The NTT gives two main reasons for a firm to internationalize production: market access and efficiency-seeking within the frameworks of horizontal and vertical FDI (Figure 3).

Horizontal FDI refers to producing goods in foreign countries when the benefits of producing abroad outweigh the losses of economies of scale from producing at home. Access to new markets seems to be a more common reason for multinational FDI activity. In this case, horizontal FDI occurs mostly between developed countries with similar factor endowments and market size. The proximity of the host markets allows firms to save trade costs but induces the fixed costs of creating a new plant abroad. In fact, MNCs prefer to enter the foreign market via FDI rather than through exporting with higher trade costs. Hence, horizontal firms intend to save trade frictions (transportation costs, tariffs, and other trade barriers to entry to the host market), so horizontal FDI substitutes for trade.

Vertical FDI is related to the growing fragmentation of the production process to decrease cost. Here, MNCs locate each production stage in the country with the more competitive factors of production. Reducing transportation and operation costs between developed and developing countries boosts the efficiency-seeking strategy of the MNCs. Due to the fact that vertically integrated companies split up the production process across the different locations and to reduce trade costs, so vertical FDI completes trade.

For a long time, horizontal and vertical FDI models have been treated as two different strands in the literature. Twenty years ago, Markusen (2002) combined the horizontal and vertical models into a hybrid framework, called the Knowledge Capital Model (KC) (Figure 3). The main advantage of the $\mathrm{KC}$ is that national, horizontal, and vertical multinational firms can coexist, based on various host- and source-country characteristics. Namely, vertically integrated 
MNCs locate their headquarters services ( $\& \& D$, advertising) in the skilled-labor, capitalabundant parent country and move their unskilled-labor activities to the host country abundant in unskilled labor. When the main part of the output comes back to the home country, this two-country FDI is known as "pure vertical FDI" (Markusen, 2002). Because those vertical MNCs will re-export products back to their home country, the impact of the surrounded market potential will be ambiguous. Recently, the $\mathrm{KC}$ model was extended in many directions (Bergstrand \& Egger, 2007; Markusen, 2013). One of the most important extensions of this framework is that, in addition to the human capital, physical capital was incorporated into the FDI model.

Another important extension of the $\mathrm{KC}$ model has supported Baltagi, Egger, and Pfafermayr (2007), who implies inclusion of an agglomeration effect in the model. This type of FDI is known as a "complex vertical FDI," (Figure 3) and it occurs when a multinational firm decides to relocate the aspects of its production processes in different neighboring countries with more favorable factor conditions. Broadly speaking, the complex vertical MNCs exploit relative factor-price differentials by splitting up and relocating their production in a complex manner. As in the pure vertical model, MNCs locate their headquarters services (management, R\&D, and advertising) in the skilled-labor parent country, but in contrast to the pure model, MNCs put their unskilled-labor activities not only in the host country but also in a neighboring third country. As expected, all partners benefit - and more importantly - the third country benefits from the complex FDI model (Blonigen, Davies, Waddell, \& Naughton, 2007).

Overall, according to both horizontal and $\mathrm{KC}$ models, there is a positive relationship between similarity in relative country size and FDI activity. On the contrary, in all types of vertical models, similarity in country size does not play any role in the determination of FDI.

In general terms, theories of FDI explain only part of the determinants of FDI. Real-world trends have led to a substantially larger number of factors that trigger the FDI activity and require empirical investigation.

\section{B. Review of the empirical literature on FDI determinants}

The amount of empirical FDI literature is large, and we have referred to the most frequently cited papers for our analysis. We considered papers that distinguish robust determinants of FDI distribution in the EU, particularly, in the NMS. We mainly examined trade gravity literature that allowed us, by analogy, to establish and test causal links between bilateral FDI flows and their determinants in selected countries. We also studied papers that recognize EU membership as a key determinant of increasing FDI inflows in the NMS. Consistent with the highly recommended trade papers (Anderson \& Van Wincoop, 2003; Yotov et al., 2016) and FDI studies (Blonigen et al., 2007; Brainard, 1997; Pain, 1993; Welfens \& Baier, 2018), we 
confirmed that the best fitting model for estimating determinants of bilateral FDI flows is a gravity model. Namely, canonical gravity models indicate a negative impact of the geographical distance between the countries of origin and destination. Just the opposite, there is a positive impact of GDP on FDI flows, in our case.

In the early days, the standard gravity model was applied mostly to horizontal FDI (Blonigen, 2005; Blonigen et al., 2007), but recent methodology of the structural gravity model provides further foundations that combine horizontal and vertical FDI (Baier, Yotov, \& Zylkin, 2019; Bergstrand \& Egger, 2007; Bruno, Campos, Estrin, \& Meng, 2017; Carr, Markusen \& Maskus, 2001), setting KC and complex vertical FDI.

Despite the fact that the FDI patterns show clear gravity characteristics, the empirical literature focuses mainly on estimation of the trade gravity model and only partly focuses on FDI. The most influential study in this area comes from Baier and Bergstrand (2007), who first designed a panel data FDI analysis and showed that an instrumental variable approach is not sufficient due to the endogeneity issue. In parallel with trade literature, many of the current FDI models present challenges with gravity estimations and suffer biases, which should be avoided. To do so, we extended earlier literature and applied for FDI gravity model practice recommendations from some influential new papers (Anderson, Larch, \& Yotov, 2017, 2019; Baier et al., 2019). Specifically, we used an estimation of the structural FDI gravity model, modified to account for the multilateral resistances with appropriate set fixed effects. For FDI gravity, this approach has not been massively applied. Thus, we implemented these latest developments from the literature.

To obtain reliable estimates of the FDI gravity model, we first created a model with country-specific fixed effects to cover the origin- and destination-country individual factors. Second, to adequately control for the dynamic forces in our model, we combined country-specific fixed effects with time. Third, we added pair-fixed effects as a powerful tool to avoid endogeneity and control for all time-invariant bilateral costs. In the end, we tested a model with a full set of fixed effects with mixed ordinary least squares (OLS) and Poisson PseudoMaximum-Likelihood (PPML) estimators.

One clear drawback of the current practice of estimating an FDI model is the presence of zero and negative values in the FDI data. In this case, the widely used OLS estimator is not acceptable because data is simply dropped from the estimation sample when the values are transformed into a logarithmic form. Often, authors (Blonigen et al., 2007; Campos \& Kinoshita, 2008; Davies, 2003) avoided this challenge by measuring FDI as a stock variable or by using MNCs affiliate sales as a dependent variable. By quantifying FDI in stock metrics, all positive and negative changes in FDI values were offset during the year. It could be a decision, but FDI stock is a static variable that implies an investment position of a country only at one specific time, at the end of the year, for example. Multinational affiliate sales 
(Asiedu, 2006; Carr, Markusen, \& Maskus, 2001; Gupta, 2017) identified effects of the plant location decision and represented more firm-level polices, rather than macro-level objectives.

Alternatively, FDI is measured as a share of FDI values in GDP or taken in the model as a variable of FDI inflows per capita. Sometimes, FDI flows can be quantified as a percentage of gross fixed capital formation for the country (Contessi \& Weinberger, 2009). However, these variables provide a measure of the relative size of FDI. To estimate models for the total value of FDI and its dynamic patterns, a flow variable is a better metric for FDI. From this point of view, we extended the FDI literature (Brainard, 1997; Dellis, Sondermann, \& Vansteenkiste, 2017; Wong \& Tang, 2011) and suggested a value of FDI flows as a dependent variable, which would also be more appropriate for measuring integration.

On the contrary, the value of FDI flows is a dynamic variable and should be expressed in logarithmic form. The challenge of negative and zero FDI values are also sustained. The problem has become more pronounced recently because there is a considerable decline and disinvestment in global FDI flows across all countries. To avoid the negative magnitude for logarithmic transformation, often negative and zero FDI values are removed from the sample. As a result, disinvestment or reinvestment outside the country is not counted, and FDI inflows may be underestimated. The specification becomes theoretically inconsistent.

As an econometric solution, we suggest replacing negative numbers of FDI flows with a very small constant, the value of one dollar, for instance. This approach is convenient and could be effective for our model because the dependent variable is measured in millions and adding a completely arbitrary value does not disturb the interpretation of the coefficients. Even the double-log model can be estimated without throwing these country pairs out of the sample.

To solve the problem of zero FDIszero FIDs, we followed Silva and Tenreyro (2006) by using the PPML estimator, which is also a valid method to account for the presence of heteroscedasticity in the sample.

While the main gravity determinants of FDI are mostly established in previous studies, the question of how EU membership affects FDI inflows to the accession countries remains uncertain. Initially, empirical studies for selected countries included a cross-country analysis and treated the entire region jointly (Brakman, 2008; Smarzynska \& Wei, 2000). Later, some authors identified the main reasons for inward FDI flows to a single country or group of countries in the EU (Cieślik, 2017, 2019; Pirlogeanu, 2017). The most advanced recent study is the paper by Bruno et al. (2017), in which the authors create a model for bilateral FDI flows of 35 OECD countries from 1985 to 2012 with pair- and time-fixed effects. They applied the study directly to BREXIT, assuming that losses will be opposite to the gains from EU membership. Another important study about the effects of BREXIT on FDI flows in the EU comes from Welfens and Baier (2018), where the authors examined the period from 1985 to 2012 for a data set of 34 OECD countries, using PPML dyadic fixed estimations. In contrast to 
our goal, these papers emphasized the impact on FDI of leaving - instead of joining - the EU.

A recently published working paper by Sondermann and Vansteenkiste (2019) concluded that bilateral FDI inflows are at least 50\% higher if both host and source countries are in the EU. This is mainly determined through the effects of reducing trade costs and specific FDI factors.

While it is important to examine this area as a discussion about increased protectionism and while the role of EU membership is not equal for all EU members, we created and estimated diverse models. In addition to the previous literature (Bevan \& Estrin, 2004; Bergstrand, Larch, \& Yotov, 2015; Bruno et al., 2017), we split the impact of EU integration among the new and old EU member states. For this, we used various methods and compared our results with each other as well as with existing studies. Moreover, we showed that the announcement about future EU enlargement is even more statistically powerful for FDI activity than an official accession date.

\section{Empirical Analysis of FDI Determinants in the Selected EU Countries}

\section{A. Gravity model of bilateral FDI flows}

To investigate the key factors that affect FDI, we present a series of empirical applications that estimate FDI determinants. More importantly, the EU membership effects in selected countries are estimated. Because the essential FDI gravity model was estimated with OLS (Bergstrand \& Egger, 2007), we started from this traditional estimator. We used a partial equilibrium approach and preferred panel data analysis that also has the advantage of mitigating heterogeneity across countries. The theory does not have FDI implications for structural gravity estimations. By making an analogy with a new trade gravity approach for a non-linear equation, we included "remoteness indexes" or multilateral resistances, which consistently aggregate trade costs and FDI barriers to the country. Accordingly, changes in trade policy anywhere in the global system may impact FDI in any country.

To control for unobservable country-specific factors, we first included host-, origin-fixed effects, and time dummies. Next, we employed a flexible country-pair fixed effects approach to control for all time-invariant bilateral variables. To provide robustness, the regression is clustered by country pairs to account for any intra-cluster correlations at the country-pair level. Finally, we employed PPML for the model combining host- and source-time fixed effects with pair-fixed effects.

Following the idea that the impact of determinants on FDI depends on the FDI strategy, 
we can suppose that two main groups of FDI determinants become crucial: the economic size of the country (for horizontal FDI) and the variables of factor endowments (for vertical FDI). Thus, the coefficient of the GDP is expected to be positive for the host country. Similarly, a greater labor cost makes the cost of production higher and hence causes less FDI. EU membership as a reason for FDI liberalization increases FDI inflows. Applying it for gravity theory, there is a positive correlation between FDI inflows and GDP, while FDI inflows and distance are negatively correlated. FDI is inversely related to FDI barriers.

Our FDI gravity estimation covered 39 OECD countries between 1991 and 2017. The data represents more than $70 \%$ of world FDI inflows (in millions of USD). Because all countries are OECD members, data were collected with the same methodology. Thus, the sample seems to be of relatively high quality.

Our dependent variable is bilateral FDI flows between the largest new EU member recipients (Poland, Hungary, the Czech Republic, Estonia, Slovakia, and Slovenia) and 33 origin countries. We started from the biggest investors for the selected destinations: Germany, France, Austria, the USA, UK, the Netherlands, Italy, Luxembourg, Belgium, Canada, Denmark, Australia, Chile, the Czech Republic, Estonia, Finland, Greece, Hungary, Iceland, Ireland, Israel, Japan, Korea, Mexico, Norway, New Zealand, Poland, Portugal, Slovakia, Spain, Sweden, Switzerland, and Turkey. The main part of the sample is based on FDI inflow data by partner country from the OECD BMD4 data set over the period 1998-2013. To obtain the required level of disaggregation and provide consistent results, we extended the sample and collected the earlier (1991-1997) and the later (2014-2017) bilateral FDI data from national central banks. Overall, a number of observations was 33 (sources)*6 (hosts)*27 (years) $=5,346$. Missing FDI values were reflected by zeros (Bevan \& Estrin, 2004).

To estimate our FDI gravity model, FDI data was merged with the World Development Indicators in terms of the GDPs of the host and source countries, measured in millions of USD. As a proxy for labor costs, we used unit labor costs (ULC) data from the OECD, calculated as the ratio of total labor compensation per hour worked to output per hour worked. The gravity bilateral characteristics (distance, colony, and common language) came from the CEPII data set.

Because negative FDI flows have real economic meaning, this data cannot be eliminated without losing consistency. For our purposes, we also could not set negatives to zero because it would mean that the investment relationships between host and origin countries did not exist. Unlike true zero investment, we suggest transforming negative FDI flows to \$1. Because FDI and GDP are measured in millions, adding a completely arbitrary value should not disturb the consistency of the model. While it is indeed a strong assumption, we provide estimates for both the negative-eliminating model as well as the transforming-negatives model. We prove that dropping negatives flows would result in bias. In contrast, the estimation FDI as \$1 will be remarkably stronger than treating negatives as zero. 
Our baseline FDI gravity model with a 1-year interval data (specification 1) is:

$$
\begin{aligned}
\text { lnFDI }_{i j t}= & \beta_{0}+\beta_{1} \text { lnGDPHost }_{i t}+\beta_{2} \text { GDPOrigin }_{j t}+\beta_{3} \text { lndist }_{i j}+\beta_{4} \text { comlangoff }_{i j} \\
& +\beta_{5} \text { colony }_{i j}+\beta_{6} \text { smctry }_{i j}+\beta_{7} U L C_{i t}+\beta_{8} E U \_m e m b_{i j t}+\beta_{9} E_{-} \text {pair }_{i j t} \\
& +\beta_{10} \text { EU_Host }_{i t}+\beta_{11} E E A_{i j t}+\varepsilon_{i j t},
\end{aligned}
$$

where $\ln F D I_{i j t}$ is the logarithm of bilateral FDI inflows to the host country $i$ from origin country $j$ at time $t . \beta_{0}$ is a constant term, ln GDPHost $_{i t}$ and GDPOrigin $j$ are the logarithms of the GDP values of host and origin countries, respectively; lndist $_{i j}$ is the logarithm of bilateral distance $(\mathrm{km})$ between capitals of countries $i$ and $j$; comlangoff $f_{i j}$ denotes a dummy variable for the existence of a common official primary language between destination $i$ and origin $j$ countries; colony $y_{i j}$ is a dummy variable capturing the presence of colonial relationships between countries $i$ and $j$; scmctry $_{i j}$ is an indicator if countries $i$ and $j$ were or are the same country; $U L C_{i t}$ is the unit labor cost in the host country $i$; and $\varepsilon_{i j t}$ is an error term.

The main relationship of interest is the impact of EU membership on FDI. Thus, we try to provide a full set of all possible effects. Besides the traditional dummy variable $E U_{-} p a i r_{i j t}$, that takes a value of 1 if only both $i$ and $j$ countries are in the EU at time $t$; we further consider a dummy variable $E U_{-} m e m b_{i j t}$ that takes a value of 1 if origin country belonged to the EU at time $t$ and the host country does not, or vice versa, and it is zero otherwise. We also added a binary variable, EU_Host ${ }_{i t}$, that takes a value of 1 if the host country is in the EU and zero otherwise. To provide robustness, we include a binary variable, $E E A_{i j t}$, if both countries at time $t$ are in the European Economic Area (EEA). The correlation between all EU dummies does not exceed $45 \%$, and the test for multicollinearity is at the sufficient level of 1.73 .

We used various traditional and modern empirical techniques for estimating our model. Table 1 presents the first estimation outcomes. 
Table 1. Estimation Results of FDI Gravity Equation

\begin{tabular}{|c|c|c|c|c|c|}
\hline Model & (1) & (2) & (3) & (4) & (5) \\
\hline $\begin{array}{c}\text { Estimator } \\
\text { Dependent variable }\end{array}$ & $\begin{array}{l}\text { OLS } \\
\operatorname{lnFDI}\end{array}$ & $\begin{array}{l}\text { RMTNS } \\
\text { lnFDI }\end{array}$ & $\begin{array}{c}\text { PPML1 } \\
\text { FDI=1 USD } \\
\text { if } \mathrm{FDI}<0\end{array}$ & $\begin{array}{c}\text { PPML2 } \\
\mathrm{FDI}=0 \\
\text { if } \mathrm{FDI}<0\end{array}$ & $\begin{array}{l}\text { PPML3 } \\
\mathrm{FDI}= \\
\text { if } \mathrm{FDI}<0\end{array}$ \\
\hline \multirow[t]{2}{*}{ lndist } & -0.5340 & -0.7443 & -0.6137 & -0.6147 & -0.5483 \\
\hline & $(0.0802)^{* *}$ & $(0.2537)^{* *}$ & $(0.1792)^{* *}$ & $(0.1794)^{* *}$ & $(0.1747)^{* *}$ \\
\hline \multirow[t]{2}{*}{ comlang_off } & -0.5353 & -0.3621 & -2.5492 & -2.5462 & -2.6470 \\
\hline & $(0.3953)$ & $(0.3936)$ & $(0.3759)^{* *}$ & $(0.3765)^{* *}$ & $(0.3659)^{* *}$ \\
\hline \multirow[t]{2}{*}{ colony } & 1.8270 & 1.7922 & 0.8108 & 0.8104 & 0.6787 \\
\hline & $(0.3684)^{* *}$ & $(0.4078)^{* *}$ & $(0.2851)^{* *}$ & $(0.2854)^{* *}$ & $(0.2813)^{*}$ \\
\hline \multirow[t]{2}{*}{ smctry } & -0.3815 & -0.3111 & -0.1166 & -0.1158 & -0.0899 \\
\hline & $(0.3731)$ & $(0.3976)$ & $(0.3588)$ & $(0.3594)$ & $(0.3528)$ \\
\hline \multirow[t]{2}{*}{$\ln G D P H o s t$} & 0.3354 & 0.3464 & 0.1767 & 0.1767 & 0.1877 \\
\hline & $(0.0467)^{* *}$ & $(0.0474)^{* *}$ & $(0.0250)^{* *}$ & $(0.0250)^{* *}$ & $(0.0260)^{* *}$ \\
\hline \multirow[t]{2}{*}{ InGDPOrigin } & 0.5504 & 0.5467 & 0.4716 & 0.4724 & 0.4458 \\
\hline & $(0.0553)^{* *}$ & $(0.0565)^{* *}$ & $(0.1208)^{* *}$ & $(0.1211)^{* *}$ & $(0.1150)^{* *}$ \\
\hline \multirow[t]{2}{*}{$U L C$} & -0.0017 & -0.0419 & -0.2599 & -0.2608 & -0.2738 \\
\hline & $(0.3946)$ & $(0.3886)$ & $(0.2750)$ & $(0.2753)$ & $(0.2624)$ \\
\hline \multirow[t]{2}{*}{$E U_{-}$memb } & 0.7661 & 0.8245 & 0.7172 & 0.7175 & 0.7517 \\
\hline & $(0.1815)^{* *}$ & $(0.1768)^{* *}$ & $(0.2591)^{* *}$ & $(0.2596)^{* *}$ & $(0.2519)^{* *}$ \\
\hline \multirow[t]{2}{*}{$E U \_$pair } & 1.0777 & 1.1420 & 1.1682 & 1.1713 & 1.1046 \\
\hline & $(0.2602)^{* *}$ & $(0.2580)^{* *}$ & $(0.2920)^{* *}$ & $(0.2930)^{* *}$ & $(0.2869)^{* *}$ \\
\hline \multirow[t]{2}{*}{ EU_Host } & -0.0234 & -0.1094 & -0.1859 & -0.1897 & 0.0716 \\
\hline & $(0.2478)$ & $(0.2425)$ & $(0.2891)$ & $(0.2900)$ & $(0.2866)$ \\
\hline \multirow[t]{2}{*}{$E E A$} & -1.1824 & -1.1620 & -1.4416 & -1.4454 & -1.3083 \\
\hline & $(0.2650)^{* *}$ & $(0.2634)^{* *}$ & $(0.2753)^{* *}$ & $(0.2764)^{* *}$ & $(0.2833)^{* *}$ \\
\hline \multirow[t]{2}{*}{ REM_Host } & & 4.7585 & 6.4298 & 6.4387 & 6.0701 \\
\hline & & $(2.1758)^{*}$ & $(2.8415)^{*}$ & $(2.8455)^{*}$ & $(2.7845)^{*}$ \\
\hline \multirow[t]{2}{*}{ REM_Orig } & & 0.2634 & 0.0397 & 0.0394 & 0.0084 \\
\hline & & $(0.2699)$ & $(0.2275)$ & $(0.2278)$ & $(0.2166)$ \\
\hline \multirow[t]{2}{*}{ _cons } & -4.9067 & -44.4426 & -53.0595 & -53.1356 & -50.0844 \\
\hline & $(0.9587)^{* *}$ & $(18.0416)^{*}$ & $(23.4770)^{*}$ & $(23.5106)^{*}$ & $(23.0111)^{*}$ \\
\hline$N$ & 4016 & 4016 & 5346 & 5346 & 4469 \\
\hline $\mathrm{r} 2$ & 0.4610 & 0.4661 & 0.2400 & 0.2392 & 0.2779 \\
\hline RESET $p$-value & 0.000 & 0.001 & 0.218 & 0.215 & 0.034 \\
\hline
\end{tabular}

(source) authors' calculations with stata 15.0

(notes) standard errors in parentheses: $+p<0.10{ }^{*} p<.05$, ** $p<.01$

Column 1 reports the pure OLS results with the logarithm of FDI as a dependent variable. Most of the variables (GDP, distance, colony, similarity, and EU dummies) are statistically significant and have the signs that could be expected from the literature (Blonigen \& Piger, 
2014; Mistura \& Roulet, 2019). Modern FDI activity has many important factors. FDI is proportional to the size of both the host and origin countries. Intuitively, richer countries are more attractive targets for FDI; in contrast, they will require a larger expenditure on FDI. The elasticity of distance is -0.53 . This is less than that usually obtained for traditional trade gravity, which is between -0.7 and -1.5 (Yotov, Piermartini, Monteiro, \& Larch, 2016). In general terms, our findings confirm the gravity type of the model: FDI elasticity is positively related to the economy size (GDP of the country) and is inversely related to FDI frictions. In addition, the similarity in market size between EU countries encourages horizontal FDI. $U L C$ was chosen as the proper measure of differences in relative factor endowments, rather than simple relative wage rates, since ULC includes also non-wage labor costs. A negative correlation between FDI and $U L C$ is associated with vertical FDI. Because $U L C$ is not statistically significant and higher trade and transaction costs between EU countries discourage vertical FDI, the overall effect from the estimates is unclear.

$E U \_m e m b_{i j t}$ and $E U \_p a i r_{i j t}$ are statistically significant and positive but have a relatively higher coefficient than in the literature. Specifically, the average effect of EU membership on FDI is about $115 \%$, calculated as $(\exp (0.766)-1) * 100 \%$, while the average level for this coefficient in the OLS model is 33\% (Bruno et al. 2017). There are even more distinctive results for $E U_{-} H_{o s t}$, and $E E A_{i j t}$, which show negative effects on FDI in the EU. These facts do not reflect reality and can be explained only by heteroscedasticity or non-appreciate estimators. In this, the OLS calculation does not consider pairs of countries with negative and zero FDI flows (more than $25 \%$ of the sample). Hence, it causes the misspecification of the model that is also confirmed by a RESET test $(p=0.000)$.

Consequently, the results clearly illustrate that the OLS estimator with log-linear transformations cannot be recommended for our purposes. In contrast, the best modern gravity practices recommend the PPML estimator as an appreciation method in this case (Silva \& Tenreyro, 2006; Yotov et al., 2016). Because a dependent variable is expressed in levels, PPML also effectively handles the zeros FDI problem.

Besides the estimation challenges, OLS results with high variability and unexpected negative effects on FDI may be due to the use of incorrect specifications, which could bias the results. Our first model does not include unobservable country-specific factors and the remoteness of the host country from another, the multilateral resistances (MRs) (Anderson \& Wincoop, 2003). The reason for including MRs in our FDI model is because remoteness is directly related to transportation costs. It is closely related to the transaction costs in terms of familiarity with local market conditions. There are several ways to control for MRs.

We started with the method that is frequently used today. By analogy with international trade, we created a model with remoteness indexes, which are calculated as the logarithm of the country's average weighted bilateral distance where weights are the partner countries' 
shares of world GDP. To show the importance of MRs for our specification, we tested different samples by various methods: first, the OLS estimator and then the PPML estimator (Columns 2-5 of Table 1).

The results from the model RMTNS in Column 2 of Table 1 are mixed. Some of the coefficients are similar to those from column 1, but the impact of distance is stronger, while the effects of colony are smaller. Due to the fact that our host countries do not have a common official language with other countries in the sample, the coefficient comlangoff $f_{i j}$ is negative. The estimates on GDP of host and origin countries as well as EU dummies are positive and statistically significant. The remoteness index of the host country (REM_Host), as expected, has a significant and positive effect on FDI that means the nature of FDI is domestic market-oriented. In contrast, the coefficient of the remoteness index of the origin country (REM_Orig) is not significant that does not suggest clear vertical FDI. This asymmetric effect allows us to identify a difference between FDI and trade gravity models. However, the limitations of observation and the insufficient level of the RESET test demonstrate the potential toward bias results in the RMTNS model (column 2). The more progressive PPML estimator (Columns 3-5 of Table 1) was proposed instead.

The PPML1 estimates (Column 3) point two main conclusions. First, more often, the PPML-estimated coefficient differences are remarkably smaller than those obtained with OLS. For instance, the coefficients of the host and source countries' GDP in this model $(0.17$ and 0.47 , respectively) are not close to 1 , as is generally believed in the OLS model. Moreover, OLS exaggerates the role of colonial history and geographical proximity (Silva \& Tenreyro, 2006). For instance, in the OLS model (Column 1 of Table 1) the effect of colonial history on FDI in Europe is more than $500 \%$, while in the PPML model is more realistic at $125 \%$. Similarly, the PPML-estimated coefficient of EU membership becomes smaller, indicating a more appreciated method. Second, the RESET test, in contrast to OLS, provides no evidence of misspecification of the model ( $p=0.218$ ).

Regarding the MRs in all PPML models (Columns 3-5 of Table 1), the coefficients of the remoteness index of the host country (REM_Host) is positive and significant, while the remoteness index of the origin country (REM_Orig) are not significant and are much lower than in the RMTNS model. This is contrary to the traditional conclusion that REM_Orig has a negative effect on FDI inflows. In our case, this argument rests transaction costs that are not at a high level. In line with the modern assumption by Anderson Larch \& Yotov, 2019), we suggest that inward MRs are significant for FDI, while a negative effect of outward MRs on FDI is not pronounced. It could be that in our sample supports that are more isolated countries from the rest of the world tend to get more FDI from the EU. Thus, there are no reasons for less FDI in the selected host countries, and our estimation results are theoretically consistent and not biased. The findings show that even with control for MRs, OLS generates different 
results from the PPML.

Besides the appropriate estimation techniques, the interpretation of estimates can also be distorted by the methods of building a sample. It is necessary to illustrate how bias arises via different approaches to handling negative FDI issues. In addition to extant studies, we compared three estimates of the sample obtained by the transformation of negative FDI flows into $\$ 1$ (Column 3 in Table 1) with those generated by treating negatives as zero (column 4) and those obtained by dropping negative values from the sample (column 5). One thing to note is that the PPML-estimated coefficients of our baseline model (column 3) and estimates of transforming negative FDI into zero values (column 4) are remarkably similar. However, we cannot use the estimate because we have real zero country-pair FDI flows.

We identified a notable difference for the model with a positive subsample (Column 5). Here, first, the number of observations is smaller than in column 3: 4,469 compared with 5,346. For a relatively small sample, this is a considerable difference. As a result, most standard gravity variables (distance and common language), and some EU dummies have a distinctive effect. Second, a shrinking of the sample leads to increase $R 2$, suggesting a better fit of the empirical model. However, dropping more than $16 \%$ of our dataset significantly distorts the results, especially when combined with too many missing values in the earlier years of the analysis. Hence, comparing all possible methods, we empirically proved the most preferred resulttreating a negative value in FDI data as a very small constant, in our case, $\$ 1$.

The estimation model was chosen due to a specific research interest. The key part of our analysis is related to MRs because they aggregate bilateral costs and FDI frictions for each country and represent the endogenous structural link between FDI and trade. Multinational resistance also captures the effects of EU membership on FDI flows and, more generally, investment liberalization between countries. However, the method of controlling for the multinational resistances with remoteness indexes is often criticized because it is theoretically not correct to capture only distance as FDI frictions (Bergstrand \& Egger, 2007).

As an alternative estimation, we employed potential improvements that have been proposed in the related literature, e.g., deriving the model with time-varying host and origin-fixed effects or the model with time-invariant pair-fixed effects with time dummies (Bergstrand \& Egger, 2007 Eicher, Helfman, \& Lenkoski, 2011). More recently, Anderson et al (2017, 2019) extended the earlier recommendations for trade gravity models and suggested combining time- and country-specific fixed effects. However, due to the novelty of this suggestion for in FDI literature, there is a lack of studies using this method. As appears from FDI research, using directional time fixed effects is problematic if the researcher is interested in the effects of country-specific variables due to collinearity (Mistura \& Roulet, 2019). Consequently, authors most commonly separate country-specific fixed effects from year fixed effects for estimating FDI models (Bergstrand \& Egger, 2007; Bruno et al., 2017 Mistura \& Roulet, 2019). 
According to the complex purposes of our study and to follow modern methodology, we used both approaches as controls for MRs. First, we specified a FDI gravity model with hostand origin-country fixed effects that will absorb observable and unobservable country-specific characteristics that vary across time (changes in national policies, institutions, exchange rates) and may influence bilateral FDI. We derived our second model by adding time dummies to control for macroeconomic shocks. To keep the two parts of our paper comparable, we initially tested our models with the OLS estimator, and later - to solve zero FDI issues and the problem of heteroscedasticity - we re-estimated our specification (2) with fixed effects by the preferred PPML estimator:

$$
\begin{aligned}
F D I_{i j t}= & \exp \left[\gamma_{i}+v_{j}+t+\beta_{1} \text { lndist }_{i j}+\beta_{2} \text { comlangoff }_{i j}+\beta_{3} \text { colony }_{i j}+\beta_{4} \text { smctry }_{i j}\right. \\
& \left.+\beta_{5} E U \_m e m b_{i j t}+\beta_{6} E U \_ \text {pair }_{i j t}+\beta_{7} E E A_{i j t}\right] * \varepsilon_{i j t},
\end{aligned}
$$

Then, following the last recommendation, the gravity specification is modified with an appropriate set of host-time and origin-time fixed effects. Our next specification (3) with PPML is:

$$
\begin{aligned}
F D I_{i j t}= & \exp \left[\gamma_{i t}+v_{j t}+t+\beta_{1} \text { lndist }_{i j}+\beta_{2} \text { comlangoff }_{i j}+\beta_{3} \text { colony }_{i j}+\beta_{4} \text { smctry }_{i j}\right. \\
& \left.+\beta_{5} E E_{-} m e m b_{i j t}+\beta_{6} E U \_ \text {pair }_{i j t}+\beta_{7} E E A_{i j t}\right] * \varepsilon_{i j t},
\end{aligned}
$$

where $F D I_{i j t}$ is the absolute value of bilateral FDI inflows to the host country $i$ from the origin country $j$ at time $t ; \gamma_{i}$ encompasses the set of time-varying host-country fixed effects that account for the inward MRs $(G D P, U L C)$ and any other country-specific characteristics. The term $v_{j}$ denotes the set of time-varying source-country fixed effects, which control for the outward MRs. The inclusion of time fixed effects, $t$, is a standard to control for aggregate shocks. In line with the new approach, we combine country fixed effects with time dummies $\left(\gamma_{i t}, v_{j t}\right)$. No constant term is included in the presence of the fixed effects. lndist $_{i j}$, comlangoff $f_{i j}$, and colony $y_{i j}$ denote traditional gravity dummy variables; and $\varepsilon_{i j t}$ is an error term. The dummies, EU_pair $r_{i j t}$, EU_memb $b_{i j t}$ and $E E A_{i j t}$ are the same as in the specification (1). With the inclusion of the country-time fixed effects, we eliminate one-sided country-specific variables, to avoid the problem of collinearity. The estimates of specifications 2-3 are presented in Table 2. 
Table 2. Panel Data FDI Model with Fixed Effects

\begin{tabular}{|c|c|c|c|c|c|c|}
\hline Model & (1) & (2) & (3) & (4) & (5) & (6) \\
\hline Estimator & OLSF1 & OLSF2 & OLSF3 & PPML1 & PPML2 & PPML3 \\
\hline Dependent v. & $\operatorname{lnFDI}$ & $\operatorname{lnFDI}$ & $\operatorname{lnFDI}$ & FDI & FDI & FDI \\
\hline \multirow[t]{2}{*}{ lndist } & -0.4930 & -0.5003 & -0.4957 & -0.5851 & -0.5820 & -0.5593 \\
\hline & $(0.1748)^{* *}$ & $(0.1750)^{* *}$ & $(0.1959)^{*}$ & $(0.2318)^{*}$ & $(0.2310)^{*}$ & $(0.2116)^{* *}$ \\
\hline \multirow[t]{2}{*}{ comlang_off } & -0.9039 & -0.5852 & -0.4008 & -2.9297 & -2.3453 & -0.2022 \\
\hline & $(0.5556)$ & $(0.5529)$ & $(0.5745)$ & $(0.7881)^{* *}$ & $(0.7848)^{* *}$ & $(0.6680)$ \\
\hline \multirow[t]{2}{*}{ colony } & 0.5706 & 0.5659 & 0.5093 & 0.1884 & 0.1853 & 0.1743 \\
\hline & $(0.2222)^{*}$ & $(0.2239)^{*}$ & $(0.2618)+$ & $(0.1544)$ & $(0.1539)$ & $(0.1388)$ \\
\hline \multirow[t]{2}{*}{ smctry } & 0.1706 & 0.1474 & 0.2752 & 1.0763 & 1.0793 & 1.1829 \\
\hline & $(0.3638)$ & $(0.3643)$ & $(0.3854)$ & $(0.3276)^{* *}$ & $(0.3333)^{* *}$ & $(0.3524)^{* *}$ \\
\hline \multirow[t]{2}{*}{ EU_memb } & 0.6555 & 0.8687 & 1.0690 & 0.4160 & 0.3527 & 0.6517 \\
\hline & $(0.1083)^{* *}$ & $(0.1801)^{* *}$ & $(0.2113)^{* *}$ & $(0.1929)^{*}$ & $(0.2262)$ & $(0.2664)^{*}$ \\
\hline \multirow[t]{2}{*}{ EU_pair } & 0.9507 & 1.2782 & -4.7474 & 0.9238 & 0.9291 & -6.4578 \\
\hline & $(0.1413)^{* *}$ & $(0.2159)^{* *}$ & $(1.3198)^{* *}$ & $(0.1528)^{* *}$ & $(0.2584)^{* *}$ & $(0.4030)^{* *}$ \\
\hline \multirow[t]{2}{*}{$E E A$} & -0.9201 & -0.8119 & -0.4351 & -0.7391 & -0.6785 & -0.5699 \\
\hline & $(0.1964)^{* *}$ & $(0.2081)^{* *}$ & $(0.2712)$ & $(0.2313)^{* *}$ & $(0.2400)^{* *}$ & $(0.3551)$ \\
\hline \multirow[t]{2}{*}{ _cons } & 4.2821 & 3.8844 & 6.7089 & 6.7510 & 6.2461 & 2.7054 \\
\hline & $(1.7445)^{*}$ & $(1.7487)^{*}$ & $(1.9344)^{* *}$ & $(2.1992)^{* *}$ & $(2.1966)^{* *}$ & $(1.4939)+$ \\
\hline$N$ & 4861 & 4861 & 4861 & 5346 & 5346 & 5340 \\
\hline $\mathrm{r} 2$ & 0.4073 & 0.4198 & 0.5738 & 0.4135 & 0.4434 & 0.6660 \\
\hline Host_fe* & Yes & Yes & No & Yes & Yes & No \\
\hline Origin_fe* & Yes & Yes & No & Yes & Yes & No \\
\hline Time_fe* & No & Yes & No & No & Yes & No \\
\hline Host_time fe* & No & No & Yes & No & No & Yes \\
\hline Origin time $\mathrm{fe}^{*}$ & No & No & Yes & No & No & Yes \\
\hline $\operatorname{RESET}$ (p-value) & 0.0001 & 0.0000 & 0.0000 & 0.0000 & 0.2698 & 0.2554 \\
\hline
\end{tabular}

(source) Authors' calculations with Stata 15.0

(Notes) Standard errors in parentheses: $+p<0.10,^{*} p<.05, * * p<.01$.

Fixed effects, whose estimates, are omitted for brevity.

As seen in Table 2, which includes the full set of the fixed effects, e.g., host-country fixed effects (Host fe), source- country fixed effects (Origin_fe), time fixed effects (Time fe) in the models OLSF 1-2 and PPML 4-5, host-time fixed effects (Host_time fe), and source-time fixed effects (Origin_time fe) in the models OLSF (column 3) and PPML (column 6). This lets us verify the MRs more comprehensively.

Progressive growth of $R 2$ from one OLS model to another, as well as between PPML models, allows us to produce theoretically consistent results. Specifically, OLS models in Columns 1-2 and PPML models in Columns 4-5 fit the data relatively well; the explanatory variables account almost $50 \%$ of the observed variation in FDI flows. However, the remarkable $R 2$ rise when we add the country-time fixed effects (Columns 3 and 6) indicates that models are performing 
adequately. It is also notable that PPML estimates fit the empirical model much better than does the original OLS, even with fixed effects. For instance, $R^{2}$ for the PPML3 model (Column 6 ) is around $67 \%$, while $R^{2}$ for OLSF3 (Column 3 ) is $57 \%$. If we compare our coefficient $R^{2}$ with the results from other research in this area (Bergstrand \& Egger, 2007; Bruno et al., 2017; Jirasavetakul \& Rahman, 2018; Welfens \& Baier, 2018), we can conclude that $R^{2}$ of our OLSF models as well as of the PPML models are at exactly the same level. On average, almost $70 \%$ of the variation of FDI flows in our model is explained by the specifications.

In general, the results from Table 2 indicate sizable differences between OLS and PPML estimates in terms of magnitudes and significance. To verify how to vary estimation results according to each particular fixed effect, we start from the traditional gravity variables.

As expected, the variable distance is significantly negative and has a relatively high $\beta$ coefficient in all models. Despite the fact that the exact impact of distance on FDI is being increasingly discussed today, the OLS results (Columns 1-3), as well as the PPML estimates (Columns 4-6), imply that with an increase in distance, FDI flows decrease. We can assume that increasing distance, as a proxy for FDI frictions and transportation costs, becomes more important for investors than being closer to the country's market.

The negative estimates of the common language variable in all models suggest that for FDI in our sample this factor has a less important role. Moreover, unlike OLS, the PPML estimates of common language lose significance when we add the country-time fixed effects (column 6). These findings, as a proxy for cultural distance, are in line with papers about FDI activity in the CEECs (Borrmann, Jungnickel, \& Keller, 2005; Jirasavetakul \& Rahman, 2018). Similarly, the PPML estimates of colonial history between selected countries, which often are exaggerated by the OLS estimator (Columns 1-3), become non-significant in the PPML models (Columns 4-6). This result is in line with the most popular papers of the gravity models (Anderson \& Wincoop, 2003; Silva \& Tenreyro, 2006; Blonigen \& Piger, 2014).

Just the opposite, the OLS models underestimate the effects of being located in the same country (smctry). This variable is not significant under OLS but has a significant and positive effect on FDI under the PPML estimator (with an average enhancement effect of more than $180 \%$, Columns 4-6). All this confirms consistency and robustness of the PPML results with real economic and political developments. Namely, Slovakia and the Czech Republic both were part of the same country before 1993 (the former Czechoslovakia). Slovenia, Croatia, and Serbia were in the same country before 25 June 1991 (the former Yugoslavia). Estonia obtained independence from Russia on August 20, 1991. Obviously, the PPML control for individual time- and country-specific effects (Columns 4-6) improves the accuracy of the OLS results (Columns 1-3). These factors have a direct and indirect impact on bilateral FDI inflows in the NMS.

It is notable that whether or not fixed effects are used, there is strong evidence that the 
OLS models suffer from misspecification, while the PPML models demonstrate theoretically consistent results. A higher $R^{2}$ was found for PPML than for OLS models; hence, PPML addresses the problem of heteroscedasticity.

At the same time, both OLS and PPML techniques produce quite similar estimates of EU membership, implying a significant impact on FDI, but there are some controversial issues. For instance, when we add country-time fixed effects, the binary variable $E U$ pair that indicates EU membership for both countries at time $t$ becomes negative in both OLS (column 3) and PPML (column 6) models. At the same time, variable EU_memb that indicate EU membership for each country, shows less magnitude and a weaker positive effect. When both host and origin economies belong to the EEA in the same year, there is no positive impact EEA on FDI inflows. In this case, the $E E A$ variable is a de facto control group for our specification.

Estimates of the impact of EU membership on FDI flows are mixed but in line with recent literature (Bevan, A., \& Estrin, S. 2004; Bruno et al., 2017; Welfens \& Baier, 2018; Mistura $\&$ Roulet, 2019). In fact, there are small, negative coefficients of the variables $E U \_m e m b$ and $E U \_$pair, which could be explained with several arguments. First, individual country-specific characteristics may be more powerful for FDI inflows to the NMS than bilateral variables of participation in the European integration. Second, perhaps taking a dummy variable is not statistically enough to illustrate the results of the integration processes. Third, it is possible that since 2004 the NMS have also received FDI from outside the EU, for example, from the United States and China. In general, all these factors confirm the existence of the problem of endogeneity of EU integration that requires a more detailed analysis.

\section{B. Estimation of the impact of EU membership on FDI}

Since the early 1990s, almost half of the states were included in the EU. While the debate on whether EU integration indeed promotes FDI growth is still ongoing, the objective of this analysis is to obtain estimates of the effects of EU membership on FDI in the new member states. All existing studies estimate the effects of EU integration with an empirical gravity equation. We extended this literature in several aspects. First, we employed pair-fixed effects in our model. Most importantly, in addition to existing studies, we formulated and estimated one particularly desirable specification: FDI modeling with a full set of fixed effects. Specifically, in order to obtain more reliable FDI estimates, we simultaneously used time-varying country fixed effects as well as time-invariant pair-fixed effects. This is because the current approach of using simple country-specific or country-time fixed effects without pair-fixed effects in estimating the model of FDI generally does not address the potential endogeneity of EU integration.

The main point is that pair-fixed effects allow us to observe FDI flows from both before and after the time of the official EU enlargement. Re-evaluating our FDI model, we apply 
the PPML estimator that also accounts for heteroscedasticity. Second, along with bilateral determinants, we additionally try to separate effects of unilateral or country-specific determinants of FDI. Besides including country-specific variables (GDP, ULC), the unilateral effect is estimated by the introduction of the specific variables $E U_{-}$Host and $E U_{-} m e m b$, which represent only the one-side EU membership. There are a lot of requirements such as standards, intellectual property, and technical regulations that investors must meet after coming into the country. These measures are not bilateral and, therefore, cannot be captured by a dyadic EU_pair dummy. The major problem with the unilateral approach is that such variables would be perfectly multicollinear with a set of host-time and origin-time fixed effects.Consequently, one of these unilateral variables should be eliminated from the model. For this, we start our analysis with a basic OLS model without country-specific fixed effects and at each additional step a new feature is introduced to the initial FDI specification. Third, parallel to trade literature (Yotov, Piermartini, Monteiro, \& Larch, 2016), besides the central idea, we assume that the impact of EU integration may not be indicated at the same time as at the time of the official EU enlargement. In order to capture the possibility that the effects of the EU continue over time, the model is further modified by including FDI lags.

Consistent with our argument, we started with a basic OLS specification without any indicators of EU integration and fixed effects (4):

$$
\begin{aligned}
\text { lnFDI }_{i j t}= & \beta_{0}+\beta_{1} \text { ln GDPHost }_{i t}+\beta_{2} \text { GDPOrigin }_{j t}+\beta_{3} \text { lndist }_{i j}+\beta_{4} \text { comlangoff }_{i j}+\beta_{5} \text { colony }_{i j} \\
& +\beta_{6} \text { smctry }_{i j}+\beta_{7} U L C_{i t}+\varepsilon_{i j t}
\end{aligned}
$$

where variables are the same as variables in specification (1), except for a number of EU dummies. Then, we added a set of EU dummies and, most importantly, pair-fixed effects, and compared models among themselves. Thus, this operation allowed us to indicate the main differences in FDI activity in the selected countries both before and after EU enlargement. Due to the problem of heteroscedasticity, we applied PPML for the empirical specification of FDI levels with pair-fixed effects:

$$
\begin{aligned}
F D I_{i j t}= & \exp \left[\pi_{i j}+\beta_{1} \ln G D P H o s t_{i t}+\beta_{2} G_{D P O r i g i n}+\beta_{3} U L C_{i t}+\beta_{4} E U \_m e m b_{i j t}\right. \\
& +\beta_{5} E E_{-} \text {Host }_{i t}+\beta_{6} E U \_ \text {pair } \\
\text { ijt } & \left.+\beta_{7} E E A_{i j t}\right] * \varepsilon_{i j t},
\end{aligned}
$$

where $\pi_{i j}$ are pair-fixed effects; other variables are the same as variables in the previous specifications (2-3). The main estimates of this approach are presented in Table 3.

As seen in Table 3, the Columns 1-3 are based on the OLS technique. Columns 4-7 estimate the same specifications with PPML. As discussed earlier, all models in Table 3 were estimated without country-specific or country-time fixed effects. The specifications are divided into two 
Table 3. Estimating the Effects of EU Membership on FDI Inflows

\begin{tabular}{|c|c|c|c|c|c|c|c|}
\hline Model & (1) & (2) & (3) & (4) & (5) & (6) & (7) \\
\hline $\begin{array}{c}\text { Dependent } \\
\text { variable }\end{array}$ & $\begin{array}{l}\text { FES1 } \\
\ln F D I\end{array}$ & $\begin{array}{l}\text { FES2 } \\
\operatorname{lnFDI}\end{array}$ & $\begin{array}{l}\text { FES3 } \\
\ln F D I\end{array}$ & $\begin{array}{c}\text { PPML1 } \\
\text { FDI }\end{array}$ & $\begin{array}{c}\text { PPML2 } \\
\text { FDI }\end{array}$ & $\begin{array}{c}\text { PPML3 } \\
\text { FDI }\end{array}$ & $\begin{array}{c}\text { PPML4 } \\
\text { FDI }\end{array}$ \\
\hline lndist & $\begin{array}{c}-0.6966 \\
(0.2055)^{* *}\end{array}$ & $\begin{array}{c}-0.7443 \\
(0.2537)^{* *}\end{array}$ & & $\begin{array}{c}-0.5690 \\
(0.1706)^{* *}\end{array}$ & $\begin{array}{c}-0.6137 \\
(0.1792)^{* *}\end{array}$ & & \\
\hline comlang_off & $\begin{array}{c}-1.0794 \\
(0.4197)^{*}\end{array}$ & $\begin{array}{l}-0.3621 \\
(0.3936)\end{array}$ & & $\begin{array}{c}-3.5146 \\
(0.4143)^{* *}\end{array}$ & $\begin{array}{c}-2.5492 \\
(0.3759)^{* *}\end{array}$ & & \\
\hline colony & $\begin{array}{c}1.6262 \\
(0.4306)^{* *}\end{array}$ & $\begin{array}{c}1.7922 \\
(0.4078)^{* *}\end{array}$ & & $\begin{array}{c}0.6728 \\
(0.3051)^{*}\end{array}$ & $\begin{array}{c}0.8108 \\
(0.2851)^{* *}\end{array}$ & & \\
\hline smctry & $\begin{array}{l}-0.3259 \\
(0.4112)\end{array}$ & $\begin{array}{l}-0.3111 \\
(0.3976)\end{array}$ & & $\begin{array}{l}-0.1346 \\
(0.3767)\end{array}$ & $\begin{array}{l}-0.1166 \\
(0.3588)\end{array}$ & & \\
\hline lnGDPHost & $\begin{array}{c}0.4537 \\
(0.0521)^{* *}\end{array}$ & $\begin{array}{c}0.3464 \\
(0.0474)^{* *}\end{array}$ & $\begin{array}{c}0.0276 \\
(0.0230)\end{array}$ & $\begin{array}{c}0.1796 \\
(0.0257)^{* *}\end{array}$ & $\begin{array}{c}0.1767 \\
(0.0250)^{* *}\end{array}$ & $\begin{array}{c}0.0135 \\
(0.0233)\end{array}$ & $\begin{array}{l}-0.0058 \\
(0.0263)\end{array}$ \\
\hline $\ln G D P O$ & $\begin{array}{c}0.6435 \\
(0.0545)^{* *}\end{array}$ & $\begin{array}{c}0.5467 \\
(0.0565)^{* *}\end{array}$ & $\begin{array}{l}-0.0619 \\
(0.0966)\end{array}$ & $\begin{array}{c}0.5519 \\
(0.1105)^{* *}\end{array}$ & $\begin{array}{c}0.4716 \\
(0.1208)^{* *}\end{array}$ & $\begin{array}{c}0.9968 \\
(0.2565)^{* *}\end{array}$ & $\begin{array}{c}0.9014 \\
(0.4329)^{*}\end{array}$ \\
\hline ULC & $\begin{array}{l}-0.0897 \\
(0.4035)\end{array}$ & $\begin{array}{l}-0.0419 \\
(0.3886)\end{array}$ & $\begin{array}{l}-0.1628 \\
(0.4531)\end{array}$ & $\begin{array}{l}-0.3105 \\
(0.2829)\end{array}$ & $\begin{array}{c}-0.2599 \\
(0.2750)^{*}\end{array}$ & $\begin{array}{c}-0.4421 \\
(0.2123)^{*}\end{array}$ & $\begin{array}{c}-0.3749 \\
(0.3214)^{*}\end{array}$ \\
\hline REM_Host & $\begin{array}{c}5.1687 \\
(2.2225)^{*}\end{array}$ & $\begin{array}{c}4.7585 \\
(2.1758)^{*}\end{array}$ & & $\begin{array}{c}8.2160 \\
(3.3393)^{*}\end{array}$ & $\begin{array}{c}6.4298 \\
(2.8415)^{*}\end{array}$ & & \\
\hline REM_Orig & $\begin{array}{l}-0.0826 \\
(0.2196)\end{array}$ & $\begin{array}{c}0.2634 \\
(0.2699)\end{array}$ & & $\begin{array}{c}-0.3993 \\
(0.1996)^{*}\end{array}$ & $\begin{array}{c}0.0397 \\
(0.2275)\end{array}$ & & \\
\hline EU_memb & & $\begin{array}{c}0.8245 \\
(0.1768)^{* *}\end{array}$ & $\begin{array}{c}0.6112 \\
(0.2334)^{* *}\end{array}$ & & $\begin{array}{c}0.7172 \\
(0.2591)^{* *}\end{array}$ & $\begin{array}{c}0.3662 \\
(0.2215)^{+}\end{array}$ & $\begin{array}{c}0.1914 \\
(0.2164)\end{array}$ \\
\hline EU_Host & & $\begin{array}{l}-0.1094 \\
(0.2425)\end{array}$ & $\begin{array}{c}0.3409 \\
(0.7019)\end{array}$ & & $\begin{array}{l}-0.1859 \\
(0.2891)\end{array}$ & $\begin{array}{l}-0.2493 \\
(0.2663)\end{array}$ & $\begin{array}{c}4.0468 \\
(0.9843)^{* *}\end{array}$ \\
\hline EU_pair & & $\begin{array}{c}1.1420 \\
(0.2580)^{* *}\end{array}$ & $\begin{array}{c}1.3474 \\
(0.2591)^{* *}\end{array}$ & & $\begin{array}{c}1.1682 \\
(0.2920)^{* *}\end{array}$ & $\begin{array}{c}0.9307 \\
(0.2421)^{* *}\end{array}$ & $\begin{array}{c}0.8021 \\
(0.2484)^{* *}\end{array}$ \\
\hline EEA & & $\begin{array}{c}-1.1620 \\
(0.2634)^{* *}\end{array}$ & $\begin{array}{c}-0.8694 \\
(0.2762)^{* *}\end{array}$ & & $\begin{array}{c}-1.4416 \\
(0.2753)^{* *}\end{array}$ & $\begin{array}{c}-0.6155 \\
(0.1854)^{* *}\end{array}$ & $\begin{array}{c}-0.5612 \\
(0.2046)^{* *}\end{array}$ \\
\hline$N$ & 4016 & 4016 & 4016 & 5346 & 5346 & 5346 & 5346 \\
\hline $\mathrm{r} 2$ & 0.4104 & 0.4661 & 0.6986 & 0.1535 & 0.2393 & 0.4545 & 0.4856 \\
\hline Pair_fe* & No & No & Yes & No & No & Yes & Yes \\
\hline Time_fe* & No & No & No & No & No & No & Yes \\
\hline RESET & 0.0000 & 0.0000 & 0.0000 & 0.1010 & 0.2180 & 0.3826 & 0.3376 \\
\hline
\end{tabular}

(Source) Authors' calculations with Stata 15.0

(Notes) Standard errors in parentheses: $+p<0.10$, $^{*} p<.05, * * p<.01$.

Fixed effects, whose estimates, are omitted for brevity.

groups according to the estimated method to compare the results within each group and then between groups.

In order to better understand how EU membership affects FDI inflows to the new EU members, we initially compared differences between the estimates within Columns 1-2 and 4-5. The main results of this comparison show that the standard gravity variables (distance, colony) in the models with EU dummies are statistically not different from the corresponding 
estimated parameters based on the sample without effects of EU memberships. It confirms that bilateral variables almost do not vary over time. Additionally, the estimates of the models 1-2 and 4-5 are similar to the findings reported in the previous chapter that confirm the correctness of our analysis. However, as compared to the estimated coefficients associated with the OLS estimations (Columns 1-2), the PPML estimates (Columns 4-5) of effects of distance are significantly smaller in absolute value. Similarly, the estimates of common language become statistically significant, and the estimate of colony decreases in magnitude but remains significant.

It is noteworthy that by adding EU dummies in the models 2 and 5 we can observe an increasing $R^{2}$, and at the same time there is a monotonic decreasing of GDP coefficients. It suggests the argument by Yotov et al. (2016), the presence of mostly small countries leads to an overall rising of OLS and PPML estimates. In other words, smaller countries tend to be more dependent on FDI activity. In addition, the GDP coefficients of host countries are lower than the estimated GDP coefficients of origin countries. For our sample, this may suggest that FDI activity in the NMS is determined not only by horizontal strategy, where FDI flows are bigger with larger EU economies, but also by vertical FDI factors.

Indeed, our estimates in Columns 5-7 highlight the importance of one more individual country characteristic: $U L C$. Remarkably, the impact of $U L C$ in the OLS models (Columns 1-3) is not significant, while adding the variables of EU integration in the PPML the estimates (Columns 5-7) become statistically significant with negative coefficients. Intuitively, investors expect that profitability of the multinationals will be higher with lower labor costs in the new EU member countries. Thus, a negative sign of $U L C$ means an increased FDI to the selected countries. Negative correlation between FDI and $U L C$ is associated with vertical FDI. These findings are in line with recent papers (Cieślik, 2019; Jirasavetakul \& Rahman, 2018). Hence, the inclusion of EU dummies and use of the PPML estimator allowed us to improve findings and partially estimate the unilateral effect of EU integration in the selected countries.

The negative coefficients and the high magnitude of EU dummies (Columns 2 and 5) could be explained, as noted before, by the problem of endogeneity. To address this, we employed pair-fixed effects in future OLS and PPML specifications (Columns 3 and 6-7 of Table 3). This minimizes the effects of all observable and unobservable time-invariant bilateral variables. To avoid perfect collinearity, all bilateral gravity variables are dropped (Columns 3, 6, 7). Also, to control for global shocks and financial crises, we added the year fixed effects, which are common for all countries (Column 7 of Table 3).

For all EU dummies, other than EU_Host, we find the effect of EU membership has been large and highly significant, increasing FDI inflows for both host and source countries by more than $100 \%$. Meanwhile, with adding pair and year fixed effects to the PPML model of FDI (Column 7 of Table 3), the unilateral variable EU_Host becomes statistically significant, wherein $R^{2}$ in column 7 doubled compared to the level of $R^{2}$ in column 3. In contrast, the other unilateral 
coefficient of EU_memb now loses its previous significance in this PPML model. Empirically, only one unilateral variable in the estimation can express the impact of EU membership. Economically, the coefficients of EU_pair and EU_Host show that EU membership has led to larger and more intensive FDI activity between EU members. Even though our results are in line with recent papers (Gupta, 2017; Welfens \& Baier, 2018), all selected countries are treated as one homogenous group, and the country-specific heterogeneity ignored. This is because it is difficult to find a suitable instrument for measuring the impact of EU membership on FDI because the coefficients vary across countries and over time. To address this limitation, in our next estimation (Table 4), more than measuring country and pair-fixed effects (Columns 1, 4), we interact country fixed effects with time (Columns 2, 5). Then we estimate a model with the full set of fixed effects (Columns 3,6). The main results are presented in Table 4.

Table 4. Panel Estimation the Impact of EU Membership on FDI with Fixed Effects

\begin{tabular}{|c|c|c|c|c|c|c|}
\hline Model & (1) & (2) & (3) & (4) & (5) & (6) \\
\hline \multirow{2}{*}{$\begin{array}{c}\text { Dependent } \\
\text { variable }\end{array}$} & FES1 & FES2 & FES3 & PPML1 & PPML2 & PPML3 \\
\hline & $\operatorname{lnFDI}$ & $\operatorname{lnFDI}$ & $\operatorname{lnFDI}$ & FDI & FDI & FDI \\
\hline \multirow[t]{2}{*}{ EU_memb } & 0.6054 & 1.0769 & 0.6813 & 0.2927 & 0.6517 & 0.8040 \\
\hline & $(0.2268)^{* *}$ & $(0.2259)^{* *}$ & $(0.2695)^{*}$ & $(0.2280)$ & $(0.2664)^{*}$ & $(0.3016)^{* *}$ \\
\hline \multirow[t]{2}{*}{ EU_pair } & 1.3459 & -4.6318 & 1.4409 & 0.8779 & -6.4578 & -6.3532 \\
\hline & $(0.2576)^{* *}$ & $(0.5547)^{* *}$ & $(0.7949)^{+}$ & $(0.2636)^{* *}$ & $(0.4030)^{* *}$ & $(0.3352)^{* *}$ \\
\hline \multirow[t]{2}{*}{ EEA } & -0.8621 & -0.3275 & -0.0884 & -0.6090 & -0.5699 & 0.0096 \\
\hline & $(0.2757)^{* *}$ & $(0.2721)$ & $(0.3127)$ & $(0.2071)^{* *}$ & $(0.3551)$ & $(0.2629)$ \\
\hline \multirow[t]{2}{*}{ lndist } & & -0.4880 & & & -0.5593 & \\
\hline & & $(0.1630)^{* *}$ & & & $(0.2116)^{* *}$ & \\
\hline \multirow[t]{2}{*}{ comlang_off } & & -0.3661 & & & -0.2022 & \\
\hline & & $(0.5606)$ & & & $(0.6680)$ & \\
\hline \multirow[t]{2}{*}{ colony } & & 0.3114 & & & 0.1743 & \\
\hline & & $(0.3043)$ & & & $(0.1388)$ & \\
\hline \multirow[t]{2}{*}{ smctry } & & 0.1615 & & & 1.1829 & \\
\hline & & $(0.3642)$ & & & $(0.3524)^{* *}$ & \\
\hline \multirow[t]{2}{*}{ _cons } & 2.5869 & 6.7679 & 0.0944 & 2.5462 & 2.7054 & -9.4506 \\
\hline & $(0.1466)^{* *}$ & $(1.9182)^{* *}$ & $(1.3217)$ & $(0.2787)^{* *}$ & $(1.4939)^{+}$ & $(1.3617)^{* *}$ \\
\hline$N$ & 4016 & 4016 & 4016 & 5346 & 5340 & 5340 \\
\hline $\mathrm{r} 2$ & 0.6984 & 0.7557 & 0.8189 & 0.4808 & 0.6660 & 0.7426 \\
\hline Host_fe* & Yes & No & No & Yes & No & No \\
\hline Origin_fe* & Yes & No & No & Yes & No & No \\
\hline Time_fe* & Yes & No & No & Yes & No & No \\
\hline Pair_fe* & Yes & No & Yes & Yes & No & Yes \\
\hline Host_time fe* & No & Yes & Yes & No & Yes & Yes \\
\hline Orig_time $\mathrm{fe}^{*}$ & No & Yes & Yes & No & Yes & Yes \\
\hline RESET & 0.0000 & 0.0000 & 0.0639 & 0.1868 & 0.2554 & 0.2356 \\
\hline
\end{tabular}

(Source) Authors' calculations with Stata 15.0

(Notes) Standard errors in parentheses: $+p<0.10, * p<.05, * * p<.01$.

Country-specific fixed effects and pair-fixed effects, whose estimates, are omitted for brevity. 
As can be seen from the estimates in Columns 1 and 4, at least two EU dummies are positively related to FDI, whereas EEA has a negative coefficient. We used EEA as an aggregate measure that captures the average effect of all regional agreements. In general, it allows us to distinguish between the separate FDI effects of EU and non-EU agreement pairs. Nevertheless, the results ignore unobserved heterogeneity and time-varying country-specific variables (FDI regulation, trade policy, FDI activity in the condition of world financial crisis, for example). Next, the interaction of country-specific fixed effects with time (Columns 2 and 5) causes the positive and significant effects of $E U_{-}$memb on FDI but negative effects of $E U_{-}$pair. However, without including pair-fixed effects, the result could be distorted by endogeneity. Finally, we estimated the OLS and PPML models with the full fixed effects together (Columns 3 and 6). It was noted that the level of $R^{2}$ and the $p$-values of the Ramsey RESET indicate that the PPML specification (column 6) is the most appreciated for this purpose. Only PPML models satisfied the misspecification test. Based on this, we provide estimates of the PPML model in column 6.

Once all fixed effects were introduced, we obtained a large, positive, and highly statistically significant estimate of the partial EU effect on FDI. Namely, the coefficient of EU_memb is 0.804, which is higher in magnitude than in Columns 1-5 and translates into a sizable FDI volume effect of $\left.123 \%(\exp (0.804)-1)^{*} 100 \%\right)$. We obtained the same result as Bruno et al. (2017), where the PPML coefficient of EU membership was 0.82, implying a positive FDI impact of 128\%. We found that, between 1991 and 2017, EU membership led FDI inflows to be greater, on average, by about $23 \%$. Meanwhile, the effect of EU_pair in our model (column 6 ) is negative and is $99 \%$ less than expected from the normal level. Despite this strong precedent, the effect of EU_pair is highly statistically significant. Our findings are not controversial and are in line with papers about EU membership (Olivero \& Yotov, 2012).

Making an analogy with trade literature (Baier et al., 2019; Baldwin, Forslid, \& Haaland, 1996), we suggest that a positive coefficient of $E U_{\_}$memb and a negative coefficient of $E U_{\text {_pair }}$ indicate that two key impacts of EU integration-FDI creation and FDI diversion-occur simultaneously in the EU. After joining the EU, the new EU member countries received more FDI from the old EU members and less from non-EU member countries. Also, for the old EU members, the lower transportation and production costs and reduced FDI frictions made FDI in the accession countries more attractive than investment in the rest of the world.

As seen in Column 6 of Table 4, despite a negative value, the coefficient of EU_pair are substantially larger than the effects of $E U_{-}$memb. Thus, we can assume that FDI diversion effects are much stronger for the old European economies than FDI creation effects for the NMS. While the accession country gains 26 potential investors, the old EU country gains only one, i.e., FDI diversion is only partly offset by FDI creation effects. However, a negative sign of the coefficient of EU pair can also indicate that EU membership is more powerfully 
determined by trade rather than FDI. Here, trade acts as a substitute for FDI and promotes a short-run strategy of horizontal FDI. Besides, the effect of participation in the EEA-i.e., access to the EEA and single market - is negative and not significant. It confirms that the EEA agreement is also formed in the pursuit of other, non-FDI goals.

In general, our estimates of the effects of EU membership on FDI are comparable to those in the related literature. For example, Cardamone and Scoppola, (2012) show that firms in the EU are mostly horizontally integrated, and the agreement may have a pronounced investment diversion effect. As in Bergstrand and Egger (2007) and Bruno et al. (2017), we obtained a similar impact of EU integration on FDI flows.

Meanwhile, FDI owing to EU enlargement was not a single event. Supposedly, the effect of EU integration on FDI may not be said to occur at the same time as official EU enlargement. From the analysis, FDI flows occurred both before and after decisions were made. This means that the impact of EU membership on FDI can be gradual. To evaluate this, we created a new FDI model with lagged variables. Additionally, to examine whether FDI, in turn, does not affect EU membership via pair-fixed effects, we tested a possible "reverse causality." For this, we created a new variable capturing the future level of EU membership. While the methodology of the influence of lagging and lead variables became popular in the trade literature (Baier et al. 2019; Yotov et al. 2016); in the FDI area it remain is scarce. We estimated phasing-in effects and future lead effects of the EU on FDI (Table 5) as a contribution to this literature.

Columns 1-3 report that partial effects of EU dummies are statistically significant, both for current and many lagged values of $E U \_m e m b$. It is remarkable, that the PPML coefficient $E U \_m e m b(\beta=0.82)$ indicates the same impact as in the previous specifications.

As seen in column 1, the PPML estimate of the future lead of EU_memb is neither economically nor statistically different from zero. Also as emphasized by Baier and Bergstrand (2007), we found a non-significant and negative coefficient of EU_lead, confirming the absence of reverse causality between FDI and EU membership. In other words, FDI does not cause a future level of EU_memb, and, consequently, EU dummies are strictly exogenous to FDI inflows. 
Table 5. Estimating the Phasing-in Effects and Future Lead Effects of EU Integration

\begin{tabular}{|c|c|c|c|}
\hline Model & (1) & (2) & (3) \\
\hline $\begin{array}{c}\text { Estimator } \\
\text { Dependent variable }\end{array}$ & $\begin{array}{l}\text { PPML_lead } \\
\text { FDI }\end{array}$ & $\begin{array}{c}\text { OLS_lag } \\
\text { lnFDI }\end{array}$ & $\begin{array}{l}\text { PPML_lag } \\
\text { FDI }\end{array}$ \\
\hline EU_memb & $\begin{array}{c}0.8062 \\
(0.3205)^{*}\end{array}$ & $\begin{array}{c}0.6945 \\
(0.3525)^{*}\end{array}$ & $\begin{array}{c}0.8242 \\
(0.4212)^{*}\end{array}$ \\
\hline EU_pair & $\begin{array}{c}-6.3673 \\
(0.3419)^{* *}\end{array}$ & $\begin{array}{c}-5.9258 \\
(1.1452)^{* *}\end{array}$ & $\begin{array}{c}-6.3215 \\
(0.3852)^{* *}\end{array}$ \\
\hline EU_lead & $\begin{array}{l}-0.1226 \\
(0.2914)\end{array}$ & & \\
\hline EU_lag1 & & $\begin{array}{l}-2.3508 \\
(2.3398)\end{array}$ & $\begin{array}{c}-3.2033 \\
(1.0645)^{* *}\end{array}$ \\
\hline$E U \_l a g 5$ & & $\begin{array}{c}0.2178 \\
(1.1265)^{*}\end{array}$ & $\begin{array}{c}2.1296 \\
(1.4879)\end{array}$ \\
\hline$E U \_l a g 10$ & & $\begin{array}{l}-0.1257 \\
(0.9635)\end{array}$ & $\begin{array}{c}1.3789 \\
(0.6125)^{*}\end{array}$ \\
\hline$E U \_\operatorname{lag} 12$ & & $\begin{array}{l}-3.2151 \\
(0.7345)^{* *}\end{array}$ & $\begin{array}{l}-3.7143 \\
(0.4132)^{* *}\end{array}$ \\
\hline$N$ & 5339 & 4839 & 5313 \\
\hline $\mathrm{R}^{2}$ & 0.7426 & 0.6024 & 0.7418 \\
\hline
\end{tabular}

(Source) Authors' calculations with Stata 15.0

(Notes) Standard errors in parentheses: $+p<0.10, * p<.05, * * p<.01$. All estimates use country-time fixed effects and pair-fixed effects, which are omitted for brevity. Column (1) applies EU lead. Columns (2) and (3) introduce phasing-in effects of EU enlargement using OLS and PPML estimators, respectively.

As seen in column 1, the PPML estimate of the future lead of EU_memb is neither economically nor statistically different from zero. Also as emphasized by Baier and Bergstrand (2007), we found a non-significant and negative coefficient of EU_lead, confirming the absence of reverse causality between FDI and EU membership. In other words, FDI does not cause a future level of EU_memb, and, consequently, EU dummies are strictly exogenous to FDI inflows.

Most important, Columns 2-3 confirm that the EU integration process is phased in over time and affects FDI inflows with lags. Indeed, despite the fact that PPML estimates usually are larger than the OLS estimation; both of them indicate that lagged EU dummies are statistically significant and mostly positive. These findings are consistent with results from related studies (Anderson et al., 2017; Bergstrand et al., 2015; Bruno et al., 2017), where the effects of integration agreements have remained significant for 10-15 years.

As seen in Columns 2-3, the average effects of $E U \_$memb more than doubled over 10 years (EU_lag10) after the Europe Agreement was signed. In the first 10 years, new EU members were attractive for FDI because they successfully combined access to a large single market and competent locations, that is, they prevailed in horizontal FDI. However, these favorable 
determinants do not automatically translate to more FDI. In years 10-12, FDI inflows into NMS reached their peak and then decreased drastically compared to the previous years (Columns 2-3 of Table 5). Due to the structure of FDI barriers little liberalization occurred in the initial period, and most of the existing frictions were eliminated in the subsequent periods. The NMS expected to catch up with the EU-15 in a short period, but they did not enough capacity and potential, and hence, they needed more FDI. Thus, investors increased their new efficiency-seeking (vertical) FDI in the accession countries.

Amid current global declines in investment, MNCs from outside the EU, mostly from East Asia, have started using accession countries for FDI as a regional export platform. FDI involves transfers of intangible assets such as know-how, brands, patents, etc., in addition to traditional forms of FDI. In this sense, FDI has become a key instrument of international policy. In general terms, the lagged coefficients of EU membership demonstrate a stable, long-term positive effect of the EU on FDI inflows, which reveal a new type of FDI, incorporating both horizontal and vertical FDI.

\section{Conclusions and Policy Implications}

In policy circles, FDI is viewed as a key driver of prosperity and development in the NMS. While many authors propose different explanations for the significant growth of FDI after EU enlargement, theoretically there are two main reasons for FDI activity distinguished in the literature: market-seeking (horizontal FDI) with the intention to access a new market, and efficiency-seeking (vertical FDI) based on differences in relative factor endowments. In addition to the existing literature, we argue that FDI in the EU, combined with international trade, creates deeper links between member and non-member economies by stimulating technology transfers and fostering the exchange of know-how, by establishing the $\mathrm{KC}$ model, and by export platform FDI. Policymakers in the EU can use the determinants of FDI verified in this paper as economic arguments for liberalization by attaching FDI or regulation for operating with transport costs or setting the EU FDI screening.

The empirical analysis is based on the theoretical explanation of FDI determinants. To capture the patterns and reasons for FDI activity in the EU, we produced a gravity model for 39 countries between 1991 and 2017. To obtain reliable results, as an extension of FDI studies, we tried to address the main challenges in the gravity estimates, namely zero and negative FDI flows, MRs that were not included, and endogeneity of EU membership. As a specific challenge of the FDI estimation, we identified a method of building a sample with negative values.

Regarding the omission of zero flows, the results clearly illustrate that the OLS estimator with log-linear transformations cannot be recommended. As a solution, the PPML estimator 
is recommended because dependent variable is placed in levels. For disinvestment, we compared three estimates obtained by the transformation of negatives into 1 USD, by treating negatives as zero; and by dropping negative values from the sample. Because the dependent variable is measured in millions, we concluded that adding a completely arbitrary value (1 USD) does not disturb the interpretation of the coefficients. This enabled us to contribute to the existing literature.

Given that the level of MRs is a general equilibrium indicator that captures the effects of FDI liberalization between any two countries, we used various techniques to control for it. First, we specified an FDI gravity model with host- and origin-country fixed effects that will absorb observable and unobservable country-specific characteristics that vary across time. Second, to adequately control for the dynamic forces in our model, we combined country-specific fixed effects with time. Third, we added pair-fixed effects as a powerful tool to avoid endogeneity and control for all time-invariant bilateral costs. In the end, we tested a model with a full set of fixed effects with the mixed OLS and PPML estimators.

The results obtained from the FDI gravity estimates have several future policy implications. For example, due to the fact that labor cost has a significant effect on attracting FDI to the NMS, it is possible that policymakers could lower wages as a way of encouraging more intensive vertical FDI in the country. However, gravity estimates show that there are many other factors that increase horizontal FDI in turn. Namely, FDI positively correlated with GDP, and negatively with distance and FDI frictions. Richer countries are more attractive for FDI, but they spent a larger expenditure and have a higher transportation costs. but they will spend a larger expenditure. In this context, if the country is attempting to attract more FDI, it would be reasonable to develop its infrastructure, production, and institutes, as well as its labor quality rather than just reducing wages.

The impact of EU membership on FDI is the critical interest of this study. We found that between 1991 and 2017 EU membership led FDI inflows to be greater, on average, by approximately 23\%. Adding various EU dummies and using PPML allowed us to partially estimate the unilateral effect of EU membership. Two key results of EU integration-FDI creation and FDI diversion-occur in the EU simultaneously. By joining the EU, the new EU member countries received more FDI from the old EU members and less from non-EU member countries.

Finally, we confirm that the impact of EU membership on FDI might not be instantaneous. The findings of lagged effects actually reinforced our proposition about the impact of EU membership on FDI. 


\section{References}

Anderson, J. E., \& Van Wincoop, E. (2003). Gravity with gravitas: A solution to the border puzzle. American Economic Review, 93(1), 170-192.

Anderson, J. E., Larch, M., \& Yotov, Y. (2019). Trade and investment in the global economy: A multi-country dynamic analysis. European Economic Review, 120. doi: https://doi.org/10.1016/j.euroecorev.2019.103 311

Anderson, J., Larch, M., \& Yotov, Y. (2017). Trade and investment in the global economy. CESifo Working Paper Series No. 6625. Retrieved from https://ssrn.com/abstract=3038677

Asiedu, E. (2006). Foreign direct investment in Africa: The role of natural resources, market size, government policy, institutions, and political instability. World Economy, 29(1), 63-77.

Baier, S., \& Bergstrand, J. H. (2007). Do free trade agreements actually increase members' international trade? Journal of International Economics, 71(1), 72-95.

Baier, S., Yotov, Y., \& Zylkin, T. (2019). On the widely differing effects of free trade agreements: Lessons from twenty years of trade integration. Journal of International Economics, 116, 206-226.

Baldwin, E., Forslid, R., \& Haaland, J. (1996). Investment creation and diversion in Europe. The World Economy, 19(6), 635-659.

Baltagi, B., Egger, H., \& Pfafermayr, M. (2007). Estimating regional trade agreement effects on FDI in an interdependent world. Journal of Econometrics, 145(1-2), 194-208.

Bergstrand, J. H., Larch, M., \& Yotov, Y. (2015). Economic integration agreements, border effects, and distance elasticities in the gravity equation. European Economic Review, 78, 307-327.

Bergstrand, J. H., \& Egger, P. (2007). A knowledge-and-physical-capital model of international trade flows, foreign direct investment, and multinational enterprises. Journal of International Economics, 73(2), 278-308.

Bevan, A., \& Estrin, S. (2004). Foreign investment location and institutional development in transition economies. International Business Review, 13(1), 43-64.

Blonigen, B. A. (2005). A review of the empirical literature on FDI determinants. Atlantic Economic Journal, 33(4), 383-403.

Blonigen, B. A., \& Piger, J. (2014). Determinants of foreign direct investment. Canadian Journal of Economics, 47(3), 775-812.

Blonigen, B. A., Davies, R. B., Waddell, G. R., \& H. T. Naughton (2007). FDI in space: Spatial autoregressive relationships in foreign direct investment. European Economic Review, 51(5), 1303-1335.

Borrmann, C., Jungnickel, R., \& Keller, D. (2005). What gravity models can tell us about the position of German FDI in Central and Eastern Europe. HWWA Discussion Papers, 328, Hamburg Institute of International Economics (HWWA). Retrieved from https://www.econstor.eu/bitstream/10419/19296/ 1/328.pdf

Brainard, S. (1997). An empirical assessment of the proximity-concentration trade-off between multinational sales and trade. The American Economic Review, 87(4), 520-544.

Brakman, S. (2008). Foreign direct investment and the multinational enterprise. Cambridge, MA; MIT Press.

Bruno, R., Campos, N., Estrin S., \& Tian, M. (2017). Economic integration, foreign investment and international 
trade: The effects of membership of the European Union. (CEP Discussion Papers, CEPDP1518). Centre for Economic Performance, London School of Economics and Political Science, London, UK. Campos, N., \& Kinoshita, Y. (2008). Foreign direct investment and structural reforms: Evidence from Eastern Europe and Latin America (William Davidson Institute Working Paper, No. 906). Retrieved from https://econpapers.repec.org/RePEc:wdi:papers:2008-906

Cardamone, P., \& Scoppola, M. (2012). The impact of EU preferential trade agreements on foreign direct investment. The World Economy, 35(11), 1473-1501.

Carr, D., Markusen, J. R., \& Maskus, K. E. (2001). Estimating the knowledge-capital model of the multinational enterprise. American Economic Review, 91(3), 693-708.

Cieślik, A. (2017). Determinants of MNE Activity in Poland: the case of firms from EU-15. Entrepreneurial Business and Economics Review, 5(1), 151-167.

Cieślik, A. (2019). What attracts multinational enterprises from the new EU member states to Poland? Eurasian Business Review, 10, 253-269.

Contessi, C., \& Weinberger, A. (2009). Foreign direct investment, productivity, and country growth: An overview. Federal Reserve Bank of St. Louis Review, 91(2), 61-78.

Davies, R. B. (2003). Tax treaties, renegotiations, and foreign direct investment. Economic Analysis and Policy, 33(2), 251-273.

Dellis, K., Sondermann, D., \& Vansteenkiste, I. (2017). Determinants of FDI Inflows in advanced economies: Does the quality of economic structures matter? (ECB Working Paper, No. 2066). Retrieved from https://ssrn.com/abstract=2990996

Dunning, J. H. (1977). Trade, location of economic activity and the MNE: A search for an eclectic approach. In The international allocation of economic activity (pp. 395-418). London: Palgrave Macmillan.

Eicher, T. S., Helfman, L., \& Lenkoski, A. (2011). Robust FDI determinants: Bayesian model averaging in the presence of selection bias. Journal of Macroeconomics, 34(3), 637-651.

Gupta, V. (2017). Exploring the relation between human capital and foreign direct investment Indian context. Journal of Industrial Statistics, 6(1), 89-107.

Jirasavetakul, L., \& Rahman, J. (2018). Foreign direct investment in new member states of the EU and Western Balkans: Taking stock and assessing prospects (IMF Working Papers, 187). Retrieved from https://www.imf.org/en/Publications/WP/Issues/2018/08/21/Foreign-Direct-Investment-in-New-Memb er-State-of-the-EU-and-Western-Balkans-Taking-Stock-and-46152

MacDougall, G. D. A. (1960). The benefits and costs of private investment from abroad: A theoretical approach. Economic Record, 36(73), 13-35.

Markusen, J. R. (2002). Multinational firms and the theory of international trade. MIT Press. https://mitpres s.mit.edu/books/multinational-firms-and-theory-international-trade

Markusen, J. R. (2013). Multinational firms. In D. Bernhofen, R. Falvey, D. Greenaway, \& U. Kreickemeier (Eds.), Palgrave Handbook of International Trade (236-262). Basingstoke, Palgrave Macmillan. https://link.springer.com/chapter/10.1007/978-0-230-30531-1_8

Mistura, F., \& Roulet, C. (2019). The determinants of foreign direct investment: Do statutory restrictions matter? OECD Working Papers on International Investment 2019/01, OECD Publishing. Retrieved from https://ideas.repec.org/p/oec/dafaaa/2019-01-en.html 
Mundell, R. (1957). International trade and factor mobility. The American Economic Review, 47(3), 321-335.

Olivero, M., \& Yotov, Y. (2012). Dynamic gravity: Endogenous country size and asset accumulation. Canadian Journal of Economics, 45(1), 64-92.

Pain, N. (1993). An econometric analysis of foreign direct investment in the United Kingdom. Scottish Journal of Political Economy, 40(1), 1-23.

Pirlogeanu, D. (2017). The determinants of foreign direct investments inflows in G7 countries. Revista Economica, 69(3), 85-93.

Silva, J. M. C. S., \& Tenreyro, S. (2006). The log of gravity. The Review of Economics and Statistics, $88(4), 641-658$.

Smarzynska, B. K., \& Wei, L. J. (2000). Corruption and composition of foreign direct investment: firm-level evidence (Policy Research Working Paper, World Bank, No. 2360). Retrieved from https://openknowle dge.worldbank.org/bitstream/handle/10986/19836/multi_page.pdf

Sondermann, D., \& Vansteenkiste, I. (2019). Did the euro change the nature of FDI flows among member states? (Working Paper Series 2275). European Central Bank. Retrieved from https://ideas.repec.org/s/e cb/ecbwps.html

Vernon, R. (1966). International Investment and International Trade in the Product Cycle. The Quarterly Journal of Economics, 80(2), 190-207.

Welfens, P. J. J., \& Baier, F. J. (2018). BREXIT and foreign direct investment: Key issues and new empirical findings. International Journal of Financial Studies, 6(2), 46-67.

Wong, K. N., \& Tang, T. C. (2011). Foreign direct investment and employment in manufacturing and services sectors: Fresh empirical evidence from Singapore. Journal of Economic Studies, 38(3), 313-330.

World Bank. (2017). World Investment Report 2018: Investment and the digital economy. United Nations, Geneva.

Yotov, Y. V., Piermartini, R., Monteiro, J. A., \& Larch, M. (2016). An advanced guide to trade policy analysis: The structural gravity model. Retrieved from https://doi.org/10.30875/abc0167e-en 